University of Nebraska - Lincoln

DigitalCommons@University of Nebraska - Lincoln

U.S. Navy Research

U.S. Department of Defense

2017

\title{
Variation in the headspace of bulk hexamethylene triperoxide diamine (HMTD) with time, environment, and formulation
}

Lauryn E. DeGreeff

U.S. Naval Research Laboratory, lauryn.degreeff@nrl.navy.mil

Michelle M. Cerreta

U.S. Naval Research Laboratory

Christopher J. Katilie

Nova Research Inc.

Follow this and additional works at: http:// digitalcommons.unl.edu/usnavyresearch

DeGreeff, Lauryn E.; Cerreta, Michelle M.; and Katilie, Christopher J., "Variation in the headspace of bulk hexamethylene triperoxide diamine (HMTD) with time, environment, and formulation" (2017). U.S. Navy Research. 112.

http://digitalcommons.unl.edu/usnavyresearch/112

This Article is brought to you for free and open access by the U.S. Department of Defense at DigitalCommons@University of Nebraska - Lincoln. It has been accepted for inclusion in U.S. Navy Research by an authorized administrator of DigitalCommons@University of Nebraska - Lincoln. 
Full length articles

\title{
Variation in the headspace of bulk hexamethylene triperoxide diamine (HMTD) with time, environment, and formulation
}

\author{
Lauryn E. DeGreeff $^{\mathrm{a}, *}$, Michelle M. Cerreta ${ }^{\mathrm{b}}$, Christopher J. Katilie ${ }^{\mathrm{c}}$ \\ ${ }^{a}$ U.S. Naval Research Laboratory, 4555 Overlook Ave. SW, Washington DC 20375, United States \\ ${ }^{\mathrm{b}}$ Former National Research Council Post-doctoral Fellow at U.S. Naval Research Laboratory, 4555 Overlook Ave. SW, Washington DC 20375, United States \\ ' Nova Research, Inc., 1900 Elkin St., Suite 230, Alexandria, VA 22308, United States
}

\section{A R T I C L E I N F O}

\section{Article history:}

Received 1 December 2016

Received in revised form 2 March 2017

Accepted 7 March 2017

Available online 8 March 2017

\section{Keywords:}

Hexamethylene triperoxide diamine

Explosive

Headspace analysis

Decomposition

\begin{abstract}
A B S T R A C T
Hexamethylene triperoxide diamine (HMTD) is a homemade peroxide explosive that has become of concern to homeland security due to the ease of synthesis and commercial availability of the materials required for its synthesis. Detection is a challenge because of its exceedingly low vapor pressure and high thermal lability. Though molecular HMTD vapor is essentially undetectable under most circumstances, HTMD is known to degrade under ambient conditions, producing volatile products that could aid in detection. This work studies the evolution of these volatile organic compounds over time and across a number of variables including synthesis method, precursors, storage time, and storage environment. The composition and quantity of these volatiles were compared across these variables. Analysis of the headspace of bulk HMTD was carried out using solid phase microextraction (SPME) with gas chromatography/mass spectrometry (GC/MS). Decomposition was also monitored by gravimetric analysis. Results herein reveal that formic acid is the most abundant decomposition product while formaldehyde is the most commonly detected across all variables. Synthesis method carried the greatest overall effect on decomposition rate and vapor profile composition.
\end{abstract}

Published by Elsevier B.V.

\section{Background}

Improvised explosive devices (IEDs) are explosive weapons created from available materials, which can be comprised of varying combinations of chemical compounds and mixtures, resulting in a diverse range of dangerous devices. Recently, the explosives commonly found in IEDs have shifted from commercial or military to homemade explosives [1]. These homemade explosives (HMEs) pose a particularly great threat due to the ease in acquiring the starting materials or components [2]. Homemade organic peroxide explosives, for example, are synthesized from commercially available materials, such as hexamine, acetone, hydrogen peroxide, and an acid, such as citric or hydrochloric acid. These compounds have not been employed as military explosives due to their high sensitivity to impact, friction, and shock; they, however, have become commonplace amongst terrorists $[1,3,4]$. Triacetone triperoxide (TATP), for example was most recently used as a primary explosive in the Paris attacks in November 2015 and the Brussels attacks in March 2016, while hexamethylene triperoxide diamine (HMTD) was used in the attempted Millennium bombing attack on the

\footnotetext{
* Corresponding author.

E-mail address: lauryn.degreeff@nrl.navy.mil (L.E. DeGreeff).
}

Los Angeles airport in 1999 and was successfully used in the 2005 London public transport bombings [5-7]. FBI specialists predict their use will become the most likely weapon for an assault against the United States as terrorists embrace the use of these peroxide explosives [8].

State-of-the-art field detection capabilities and instrumentation are essential to detecting an explosive threat, such as peroxide explosives, prior to detonation. Detection instruments are often deployed in complex environments and in the presence of background interferences requiring superior selectivity and sensitivity [1]. Instrumentation that has proven to be successful in the field include gas chromatography (GC) with chemiluminescent detection, mass spectrometry (MS), or electron capture detection (ECD), and most commonly, ion mobility spectrometry (IMS) [911]. The commonly employed method of IMS has been shown to be effective for the highly sensitive detection of low-volatility explosives [11]. This method requires the collection of explosive particulates from contaminated surfaces through the use of contact swipes, which are then introduced into the device for sample desorption, analysis, and detection $[9,10]$. The downside of this particular method is that the use of swipes, or any contact sampling method, presents a high risk for technicians sampling potentially sensitive or thermally unstable energetic materials, in addition to 


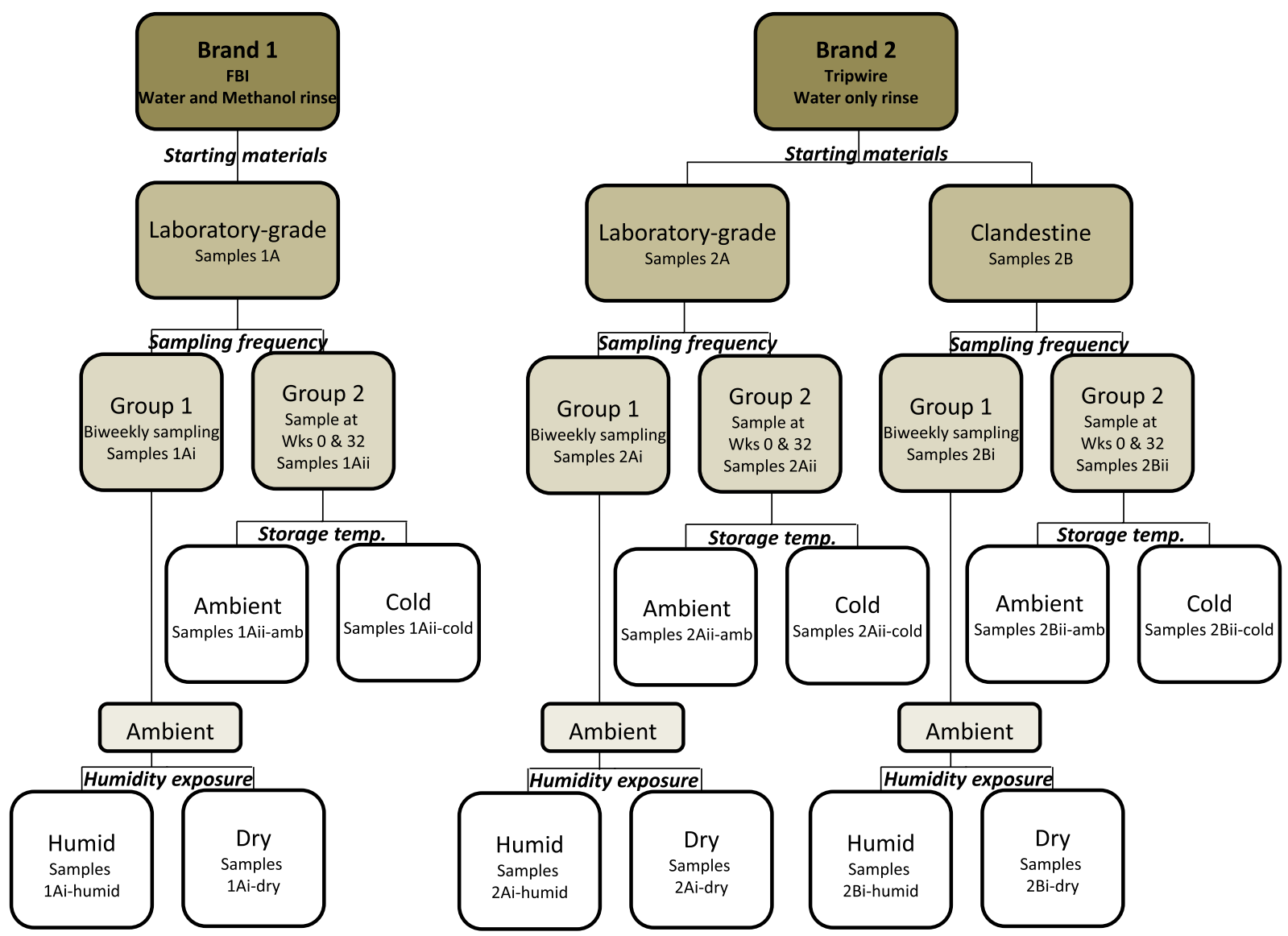

Fig. 1. Schematic of bulk HMTD division by variable, including starting material, sampling frequency, storage temperature, and humidity exposure.

a challenge for detecting buried or packaged materials that lack contaminated outer surfaces. Therefore, a more attractive approach would be an analysis technique that utilizes noncontact sampling, such as vapor sampling by canine or handheld sensors $[9,12,13]$.

Although TATP is similar to HMTD in the sense that they are both primary peroxide explosives synthesized from easily accessible precursor materials, TATP has a much higher reported vapor pressure $\left(6.31 \times 10^{-5}\right.$ atm [14]) as compared to HMTD (estimated upper limit vapor pressure near $3.9 \times 10^{-7}$ atm $\left.[15,16]\right)$, and TATP is more thermally stable than HMTD, making HMTD difficult to detect by standard methods [3]. TATP's relatively high vapor pressure ensures an increased probability of detecting the explosive when hidden or enclosed. Studies have shown that TATP has a very simple headspace vapor profile that is limited to the TATP molecule itself, allowing it to be easily detectable by conventional methods [17]. Vapor detection of TATP through non-contact sampling has been extensively explored. Scholte-Ladbeck and Karst used air sampling to collect the analyte before delivery into a liquid chromatograph [18], while Oxley et al. trained detection canines to detect cotton balls permeated with TATP vapor [19]. Additionally, chemical sensors and electronic noses have been developed, selectively detecting less than $100 \mathrm{ppb}$ of TATP [20].

The estimated vapor pressure of HMTD, while known to be very low, is still a matter of debate and has been deemed too low to be accurately measured experimentally $[15,16]$. Another challenge surrounding analytical evaluations of HMTD is its thermal instability and high sensitivity to friction. This is most likely due to the unique structure of the HMTD molecule with two parallel bridgehead nitrogen atoms that are $\mathrm{sp}^{2}$ hybridized, giving a planar struc- ture rather than pyramidal [21]. The geometry of HMTD creates a ring strain contributing to its overall sensitivity. This ring strain is also responsible for a low-temperature decomposition mechanism in which a $\mathrm{C}-\mathrm{N}$ bond cleavage occurs, as opposed to an $\mathrm{O}-\mathrm{O}$ bond homolysis which is frequently observed in other peroxide molecules $[22,23]$. The ease with which HMTD decomposes into more volatile compounds suggests that the detection of HMTD decomposition vapor products is a much more feasible alternative to direct detection of the parent molecule.

The vapor signature, or mixture of decomposition vapor products, of HMTD has seldom been reported for HMTD under ambient storage conditions. In one study, Oxley et al. identified $\mathrm{N}, \mathrm{N}^{\prime}$ dimethylformamide, N,N'-methylenebis(formamide), trimethylamine, and hexamine as decomposition products that comprise the HMTD vapor signature [16]. In another, the headspace of crude and recrystallized HMTD were examined in the presence of different levels of humidity and of different ages, and found trimethylamine and dimethylformamide being in the greatest abundance [24]. Though this study did not go into detail, it appears that variables such as humidity and age affect the presence of these decomposition products.

In the course of determining mechanisms driving HMTD decomposition, Steinkamp et al. [25] found additional volatiles contributing to the vapor signature, including formic acid, acetic acid, formamide, and formaldehyde, with formic acid being the dominant odor in the headspace of the sample. Interestingly, it was found that the HMTD vapor profile not only changed with time as the sample continues to decompose, but also under varying conditions. Building upon Steinkamp et. al., the research herein further studied the vapor profile resulting from the decomposition of 
Table 1

Formulation and synthesis protocol for each brand of bulk HMTD used.

\begin{tabular}{lll}
\hline $\begin{array}{l}\text { Formulation (starting } \\
\text { material source) }\end{array}$ & Brand 1 & Brand 2 \\
\cline { 2 - 3 } & Laboratory-grade & Clandestine $\begin{array}{l}\text { Laboratory- } \\
\text { grade }\end{array}$ \\
\hline Synthesis rinse protocol & $\begin{array}{l}\text { Rinse with water } \\
\text { and methanol }\end{array}$ & Rinse with water only \\
\hline
\end{tabular}

Table 2

Method limit of detection (LOD) for relevant analytes based on 3 times the signal-tonoise ratio of the lowest detectable mass, averaged over the length of the experiment.

\begin{tabular}{ll}
\hline Analyte & LOD $(\mathrm{ng})$ \\
\hline Formic acid & 15 \\
Acetic acid & 5 \\
Trimethylamine & 0.5 \\
Formaldehyde & 0.5 \\
Formamide & 1 \\
Dimethylformamide & 0.5 \\
\hline
\end{tabular}

HMTD over a prolonged time period of 32 weeks, and across various synthetic protocols, air exposure, storage temperatures, and humidity exposure. Such decomposition compounds have the potential to be used as target analytes for HMTD vapor detection. However, to do so, a better understanding of HMTD's vapor profile and how this profile is influenced by age, environmental conditions, and synthesis methodology must be determined in order to exploit HMTD decomposition to improve vapor detection.

\section{Materials and methods}

The evolution of volatiles in the headspace of bulk HMTD was monitored over 32 weeks. The influences of different factors associated with this decomposition were also assessed across this time period. As many "recipes" for synthesizing HMTD are available online, different starting ingredients and purification steps were studied. Exposure to ambient air, humidity, and varying temperature has also been thought to influence HMTD decomposition. For this reason, bulk material was divided, with separate portions exposed to differing humidities, temperatures, and sampling frequencies according to the following schematic (Fig. 1). Triplicate samples were prepared for each set of variables.

\subsection{Explosive handling}

WARNING! HMTD is a primary explosive that is sensitive to external stimuli, such as heat, friction, and electrostatic discharge. HMTD samples were stored in static dissipative vials and, when not in use, were held in a Department of Transportation (DoT) approved container (MK 663), and stored in an explosion-proof freezer or safe. All materials were handled behind an Explosives Personnel Shield (certified to a net explosives weight of $3.0 \mathrm{~g}$ ) using the proper protective equipment. During equilibration and sampling, the material was held in an explosion-resistant headspace sampling chamber designed at the Naval Research Laboratory [26], and placed behind the explosives shield.

\subsection{Bulk HMTD samples}

Bulk materials were provided by the Federal Bureau of Investigation - Explosives Unit (FBI) (Quantico, VA), and Tripwire Operations Group, LLC (Tripwire) (Gettysburg, PA), hereinafter referred to as Brand 1 and Brand 2, respectively. Brand 1 was synthesized from laboratory-grade chemicals, and was washed with water and dried with methanol for purification. Brand 2 was synthesized in a similar manner, but was washed with only water until the $\mathrm{pH}$ was neutralized. Two formulations of Brand 2 were provided, laboratory-grade and clandestine (Table 1). Both formulations were synthesized and purified according to the same protocols, but with different starting materials: one formulation was synthesized strictly from laboratory-grade materials, and the other from commercially available materials mimicking clandestine synthesis.

Upon receipt, all bulk materials were separated into $250 \mathrm{mg}$ aliquots and stored in $28.71 \mathrm{~mL}$ polypropylene, static dissipative vials (ESD Plastic Containers, Yorba Linda, CA). Parafilm was placed between the top of the vial and the lid. Parafilm was also wrapped around the lid to reduce the loss of volatiles from the vial.

\subsection{Sample treatment and storage}

All sampling was carried out by placing a $250 \mathrm{mg}$ aliquot of HMTD in a headspace sampling chamber for one hour, followed by a one hour extraction by solid phase microextraction (SPME). The sampling chamber had an interior volume of approximately $600 \mathrm{~mL}$ and was sealed to prevent air from moving in or out. Blank headspace samples were taken of the chamber throughout the course of the investigation. In addition to volatile extraction, the mass of each sample was recorded (XS205 Dual Range balance, Mettler Toledo, Columbus, $\mathrm{OH}$ ) at the time of removal from storage. Mass loss overtime was calculated from the gravimetric data.

Bulk materials from both Brand 1 and Brand 2 were divided into two groups, summarized in Fig. 1. Group 1 was sampled biweekly for 24 weeks, then monthly until the material was a total of 32 weeks aged. The Group 1 material was further divided into two subgroups, and each was flushed with either dried ( $0 \%$ humidity) or humidified ( $80 \%$ humidity) air through the sampling chamber at a flow rate of $135 \mathrm{~mL} / \mathrm{min}$ for a total of $1.2 \mathrm{~L}$ of air immediately after sampling and before storage. Dried and humidified airflows were generated using a Test Atmosphere Generator (HCS-401, Miller-Nelson, Livermore, CA). All materials in this group were stored at ambient temperatures $\left(20-22^{\circ} \mathrm{C}\right)$ when not in use. The samples in Group 2 were not opened regularly, and instead stored unopened for 32 weeks. This group was also subdivided into two subgroups, one being stored at ambient temperature $\left(20-22{ }^{\circ} \mathrm{C}\right)$ and the other at $-4{ }^{\circ} \mathrm{C}$

\subsection{Analysis and instrumentation}

Solid phase microextraction (SPME) (Sigma-Aldrich, St. Louis, MO) was used for the sampling of analytes in the headspace of the bulk HTMD. A divinylbenzene/car boxen/polydimethylsilocane (DVB/CAR/PDMS) - coated SPME fiber (Sigma-Aldrich) was inserted into the headspace sampling chamber in such a manner that the tip of the fiber was approximately $2 \mathrm{~cm}$ above the sample vial. Analytes were extracted for one hour under ambient conditions. The SPME fiber was removed and analytes were thermally desorbed into the inlet of a 6890 Agilent gas chromatograph (GC) with a 5975 mass spectrometer (MS) (Agilent Technologies, Santa Clara, CA) at $260^{\circ} \mathrm{C}$. The flow rate into the GC was $1.5 \mathrm{~mL} / \mathrm{min}$ with a $10: 1$ split. The GC oven was initially heated to $35^{\circ} \mathrm{C}$ and held for one minute. The temperature was then increased to $180^{\circ} \mathrm{C}$ at $25^{\circ} \mathrm{C} / \mathrm{min}$, and then to $240^{\circ} \mathrm{C}$ at $40^{\circ} \mathrm{C} / \mathrm{min}$, where it was held for a final $2.20 \mathrm{~min}$. The transfer line to the MS was held at $250{ }^{\circ} \mathrm{C}$ and the scan range was $28.5-300 \mathrm{~m} / \mathrm{z}$.

\subsection{Quantitation and data analysis}

Quantification of the total mass of analytes extracted was carried out by comparing GC/MS integrated peak areas to external calibration curves which were run weekly. Calibration curves were performed by liquid injection of $1 \mu \mathrm{L}$ of analyte standards in methanol (five replicates of five concentrations; average RSD $=7 \pm 4 \%$ )

Table 3

Permeation rates of major HMTD headspace components in ng per minute at given temperatures.

\begin{tabular}{lll}
\hline Analyte & $\begin{array}{l}\text { Permeation oven } \\
\text { temp. }\left({ }^{\circ} \mathrm{C}\right)\end{array}$ & $\begin{array}{l}\text { Permeation } \\
\text { rate }(\mathrm{ng} / \mathrm{min})\end{array}$ \\
\hline Trimethylamine & 30 & 525 \\
Dimethylformamide & 100 & 686 \\
Formic acid (high rate) & 80 & 9338 \\
Formic acid (low rate) & 40 & 500 \\
\hline
\end{tabular}

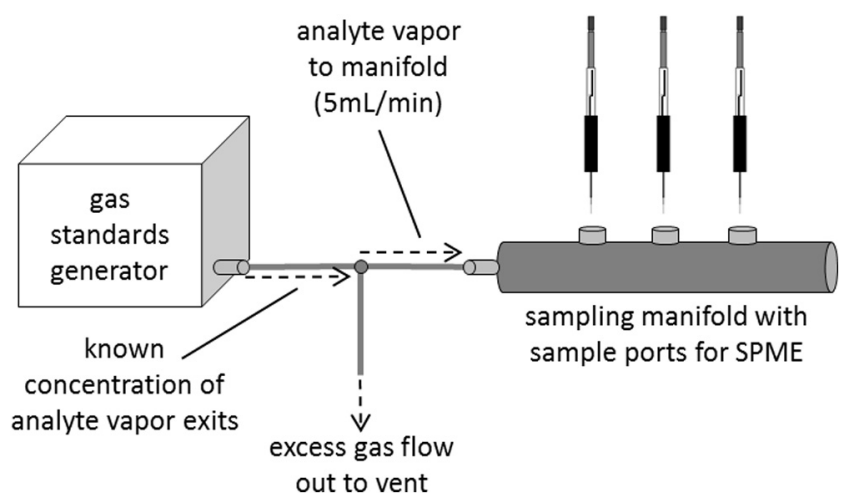

Fig. 2. Diagram of apparatus used for generating vapor calibration curve with SPME. 


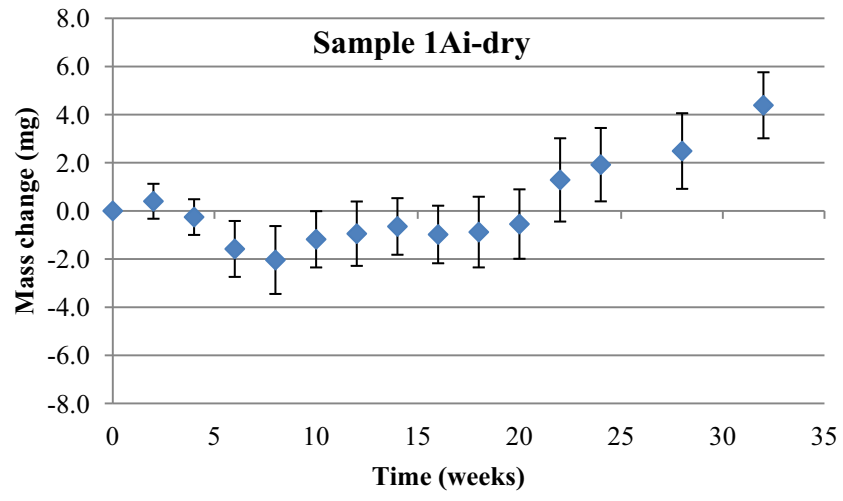

Fig. 3. Change in the mass of Samples 1Ai-dry (Brand 1, Group 1), over 32 weeks.

using the same GC/MS method previously discussed, yielding $R^{2}$ values $>0.98$. Detection limits for each analyte, defined as the mass resulting in a peak with an averaged signal to noise ratio of three, are given in Table 2 (example mass spectra given in Appendix 1).

An additional vapor calibration curve was used to estimate the vapor concentration of the major components of the analyte vapor. Permeation tubes (Kin-tek Laboratories, Inc., La Marque, TX) were obtained for formic acid, dimethylformamide, and trimethylamine. Permeation rates, as determined by Kin-Tek Laboratories, are listed in Table 3. The vapor concentration of each analyte was adjusted by flowing clean, dry diluent air using a FlexStream Modular Gas Standards Generator (Kin-Tek Laboratories). A portion of the total output from the standards generator containing known vapor concentrations of each analyte was delivered to a passivated stainless steel sampling manifold. The manifold housed three sample ports with septa for SPME sampling, and the total flow rate over the SPME fibers was maintained at $5 \mathrm{~mL} / \mathrm{min}$ over the SPME fibers (Fig. 2). The vapor concentrations of each analyte from sample materials were then estimated by comparison to the resulting calibration curves.

\section{Results}

The quantity of volatile organic compounds (VOCs) collected from the headspace of the bulk HMTD samples varied over time and with formulation. Although the laboratory conditions and sampling variables were strictly controlled, intra-sample variability was relatively high. Nevertheless, trends can be extracted from the data (see Appendix 1). The VOCs from HMTD degradation included formic acid, acetic acid, formaldehyde, formamide, dimethylformamide, and trimethylamine, with formic acid being the dominant headspace product for most samples, followed by formaldehyde.

\subsection{Storage time/formulation}

Brand 1, manufactured by the FBI Explosives Unit, is often used as a standard reference material for both research and canine detection training. This material showed very little decomposition over the time period tested, and minimal mass loss overall. Fig. 3 depicts the mass loss of Sample 1Ai-dry. The mass loss was the greatest at week 8 , and remained relatively steady at that mass through week 18. After week 18, the samples gained small amounts of mass through the duration of the experiment. These

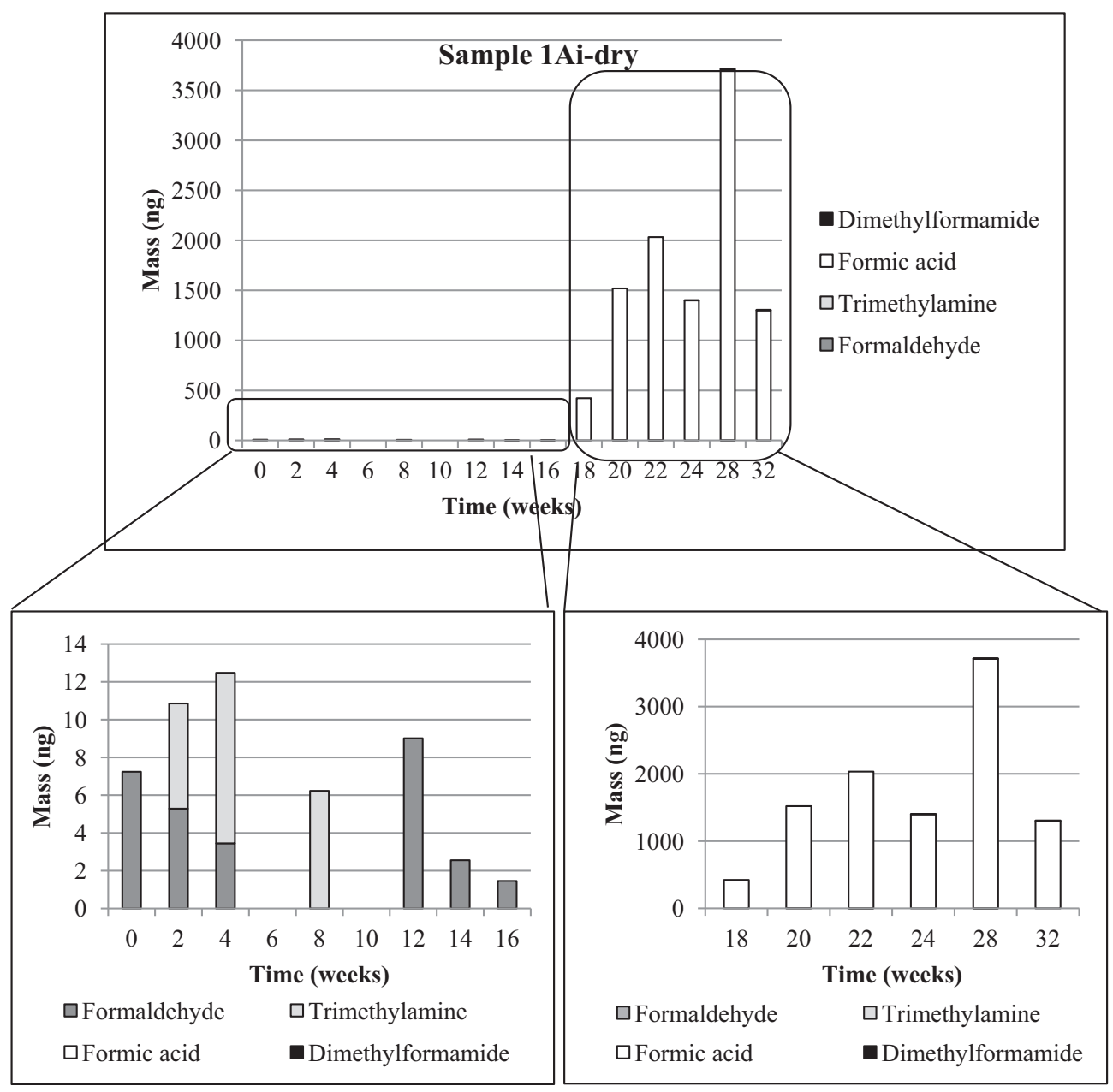

Fig. 4. Mass of volatile components detected from the headspace of Samples 1Ai-dry (Brand 1, Group 1) over 32 weeks. 


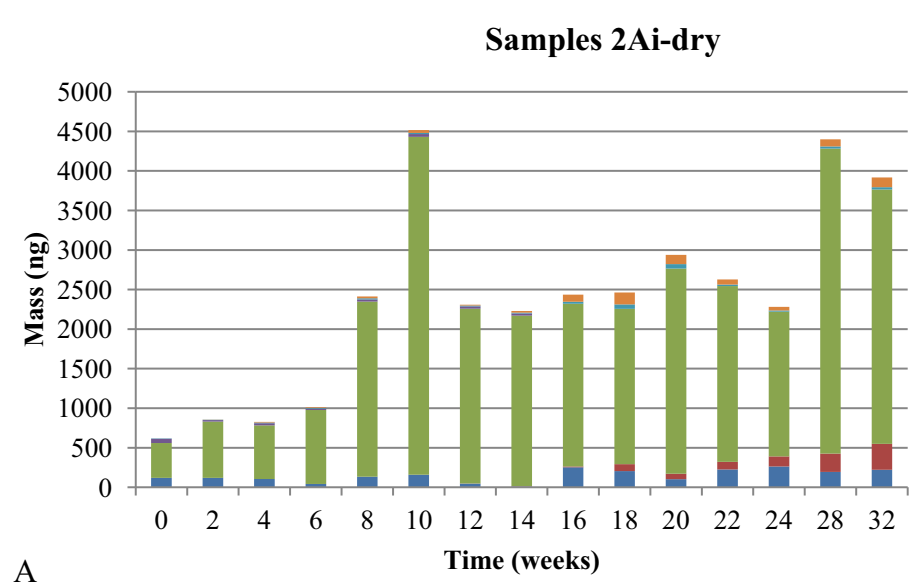

A

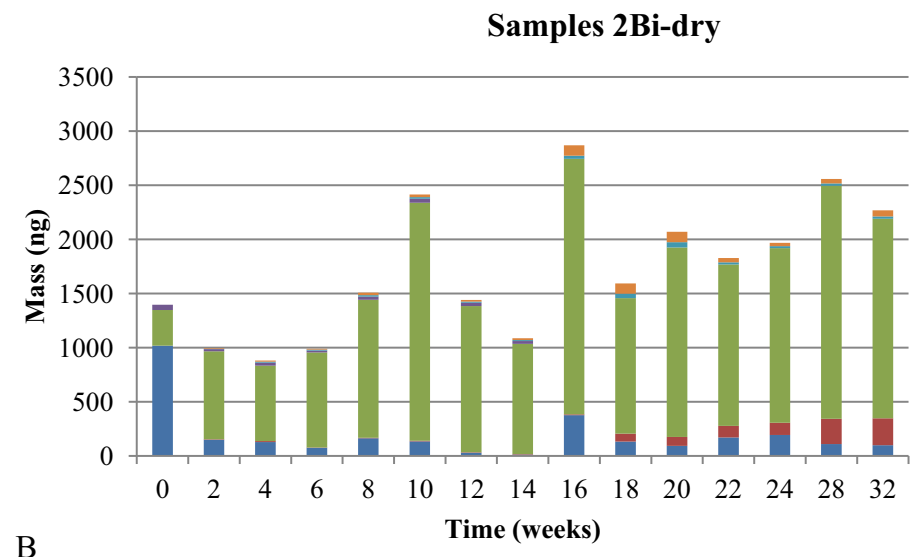

匹 Dimethylformamide

Formamide

- Acetic acid

- Formic acid

- Trimethylamine

- Formaldehyde

Dimethylformamide

- Formamide

- Acetic acid

- Formic acid

- Trimethylamine

- Formaldehyde

Fig. 5. Mass of volatile components detected from A.) Samples 2Ai-dry (Brand 2, Laboratory-grade, Group 1) and B.) Samples 2Bi-dry (Brand 2, Clandestine, Group 1) over 32 weeks.

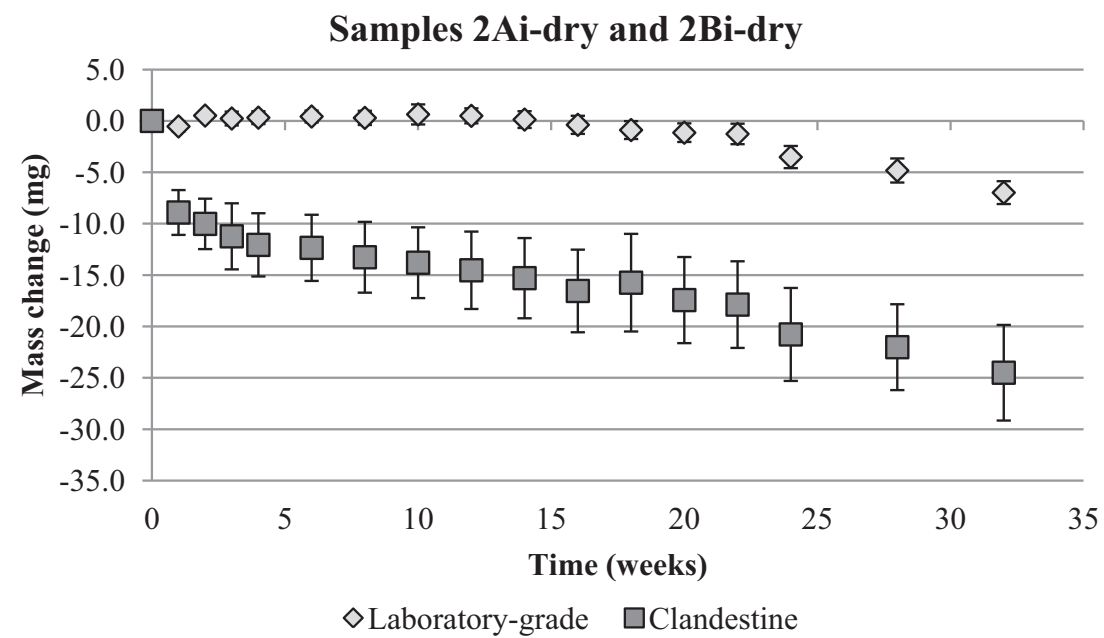

Fig. 6. Change in the mass of Samples 2Ai-dry and 2Bi-dry (Brand 2, clandestine and laboratory-grade, Group 1) over 32 weeks.

small gains could reasonably be explained as sequestration of water acquired upon opening of the vial at the time of analysis, although the samples were exposed to a stream of dried air at the end of each sampling day.

In agreement with the gravimetric data, Brand 1 yielded few decomposition products throughout much of the experiment, with individual analyte quantities often being near the limit of detection for the method, as seen in Fig. 4, for Sample 1Ai-dry. Formaldehyde was the only compound detected at week 0 and weeks 12-16. Trimethylamine was detected at weeks 2,4 , and 8 . Both of these compounds were detected at very low levels with no trends increasing or decreasing. All compounds dropped below the limit of detection at weeks 6 and 10, although very small peaks that could likely be attributed to formaldehyde and trimethylamine were noted. There was a significant change at weeks 18 and 20, where a large amount of formic acid appeared in the headspace. 
The quantity of formic acid was so great it was difficult to visualize the dimethylformamide that was also detected weeks 24-32. Formic acid continued to increase steadily through the duration of the experiment. This change in vapor profile correlates to the increase in mass seen at week 20 . It is possible that the water absorbed by the samples at this time instigated the formation of formic acid vapor in the headspace.

Both Brand 2 formulations (Samples 2Ai and 2Bi in Figs. 5 and 6) had a considerably greater quantity of degradation VOCs present and greater mass lost compared to Brand 1 (Figs. 3 and 4). Upon initial receipt of the Brand 2 samples, formaldehyde, acetic acid, and formic acid were detected, with formic acid being dominant from week 0 . Formic acid showed a marked increase at week 8 , and then again at week 28 , although the increase at week 28 could have been due to the decrease in sampling frequency at this point. The acetic acid was present in both Brand 2 formulations until week 14 , after which it was no longer detectable.

Initially, a greater amount of formaldehyde was measured in the clandestine sample (Sample 2Bi-dry; Fig. 4B) compared to the laboratory-grade samples (Sample 2Ai-dry; Fig. 4A), presumably from hexamine impurities, a precursor. By week 4 , the quantity of formaldehyde in the clandestine sample was reduced to a level similar to that of the laboratory-grade sample. This level remained relatively constant for both formulations over the duration of the sampling period.

Formamide, dimethylformamide, and trimethylamine all showed a steady increase over the sampling period. There was no significant difference between the quantity of the formamides in the clandestine vs. laboratory-grade samples, and the total mass extracted from the headspace only increased moderately. The amount of trimethylamine increased significantly from below the limit of detection to greater than $300 \mathrm{ng}$ over the 32 weeks. Trimethylamine was detected earlier in the clandestine samples than in the laboratory-grade samples, appearing above the limit of detection at weeks 2 and 12, respectively. The quantity by week 32 , however, was similar between these two sets of samples.

While the total VOCs produced from the clandestine and laboratory-grade samples were similar to one another, the mass lost was divergent (Fig. 6). The laboratory-grade samples had very little or no mass lost until week 20. There was even a slight gain in mass due to some hygroscopicity of the HMTD or its decomposition products. After week 20 , the mass change became significant and steadily increased through the end of the study. The mass loss seemed to have no notable impact on the quantity of VOCs present

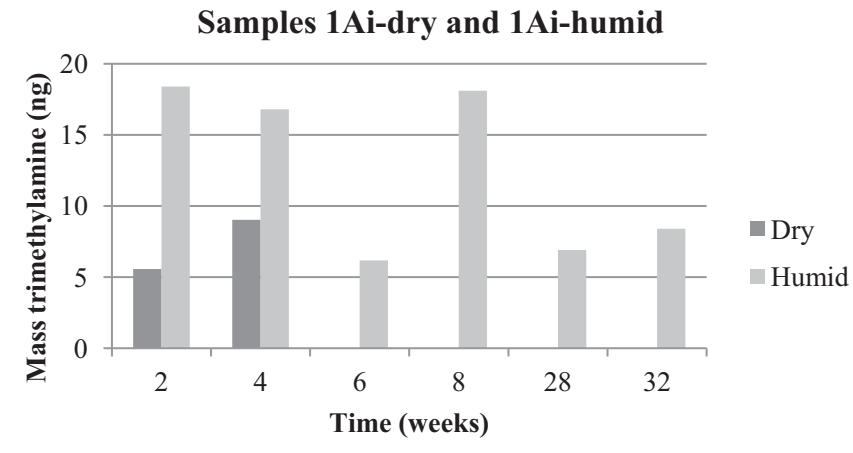

Fig. 8. Comparison of trimethylamine collected from the headspace of Samples $1 \mathrm{Ai}$ dry and 1Ai-humid (Brand 1, Group1).

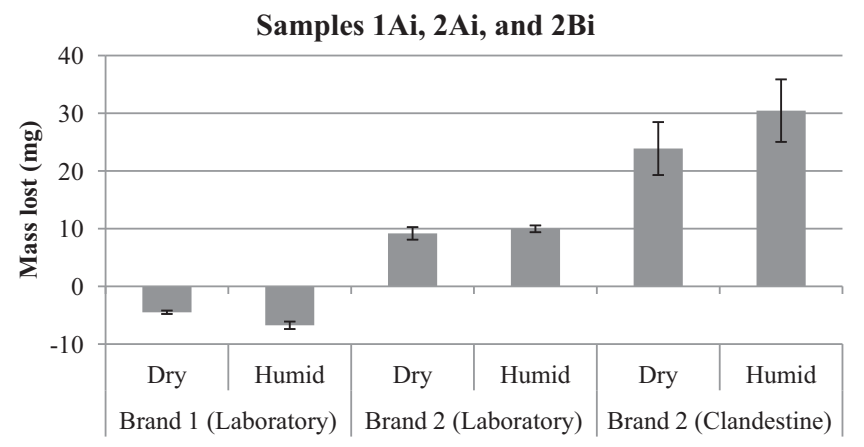

Fig. 9. Mass lost from Samples $1 \mathrm{Ai}, 2 \mathrm{Ai}$, and $2 \mathrm{Bi}$ (dry and humid) after 32 weeks of periodic exposure to dried or humidified air.

at week 20. The clandestine samples had measurable mass loss from receipt. Based on the slope of the curve, there was a brief slow in this loss at week 6 corresponding to the reduction of formaldehyde in the headspace, and another small inflection in slope at week 20, though, again, this does not appear to correlate to a change in VOCs present. Overall, there was significantly more mass lost from the clandestine samples $(27.2 \pm 5.0 \mathrm{ng})$ by the end of the studied compared to the laboratory-grade samples $(9.58 \pm 0.84 \mathrm{ng})$.

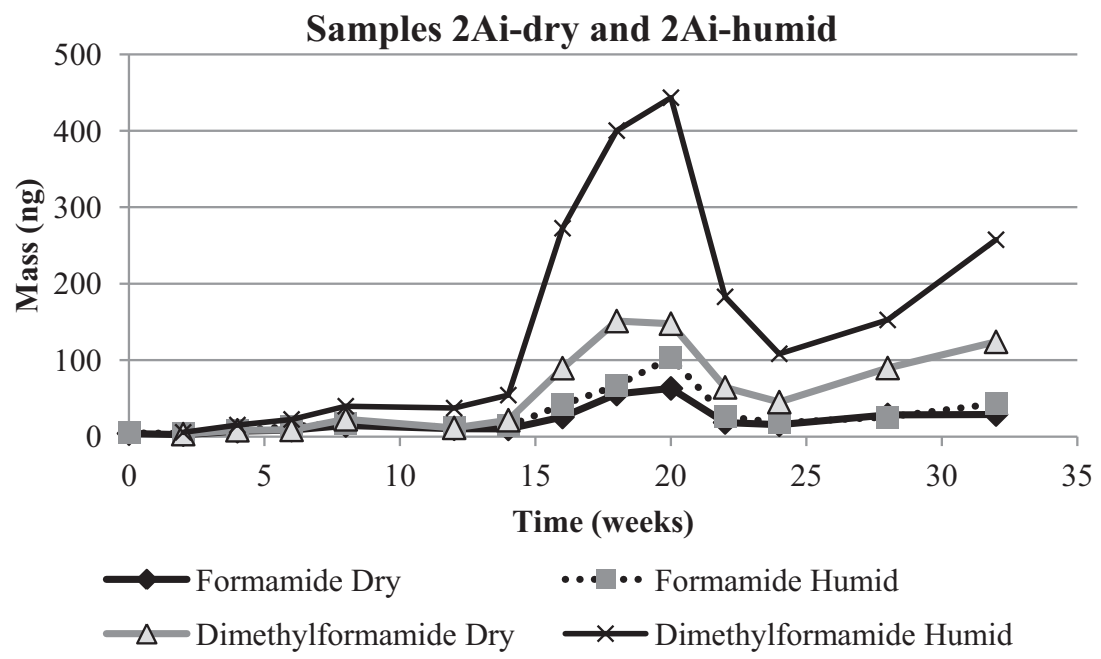

Fig. 7. Comparison of formamides collected from the headspace of Samples 2Ai-dry and 2Ai-humid (Brand 2, laboratory-grade, Group1). 


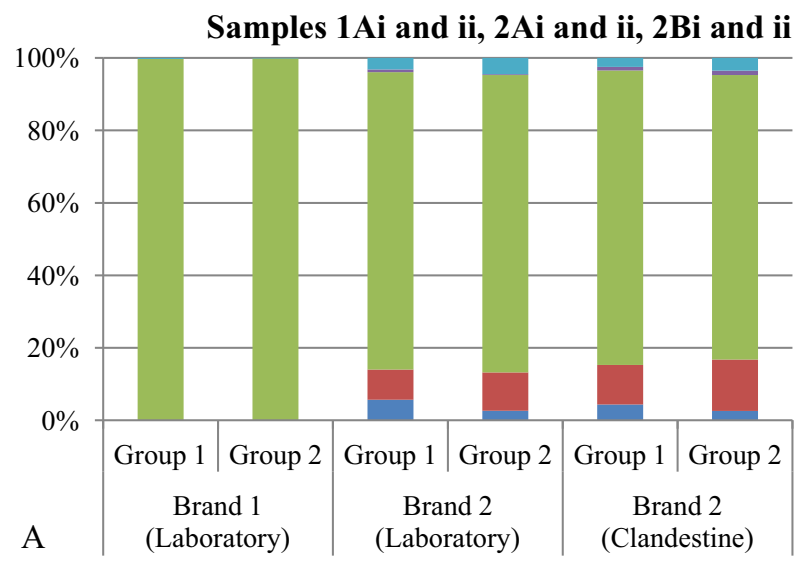

\section{- Dimethylformamide \\ - Formamide \\ Formic acid \\ - Trimethylamine \\ - Formaldehyde}

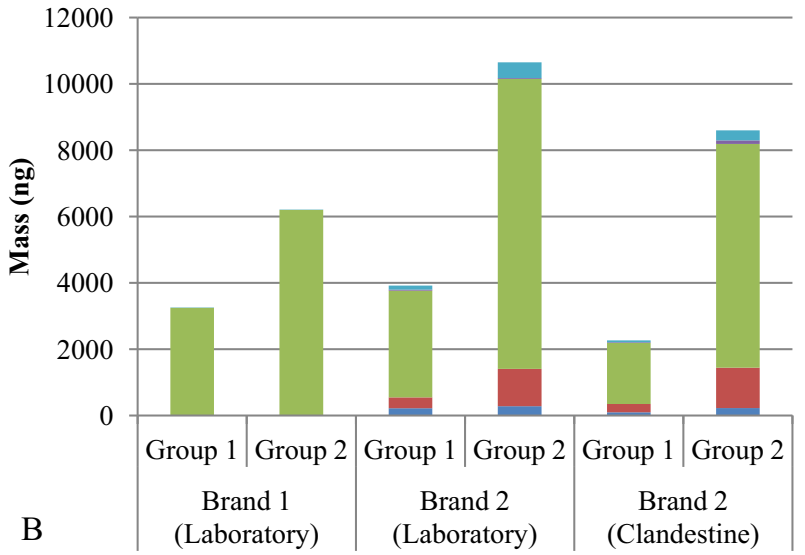

Dimethylformamide

- Formamide

Formic acid

- Trimethylamine

- Formaldehyde

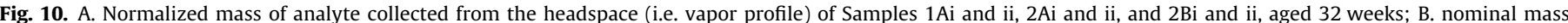

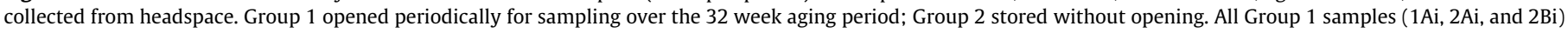
were exposed to dry air. All Group 2 samples (1Aii, 2Aii, and 2Bii) were stored at ambient temperatures.

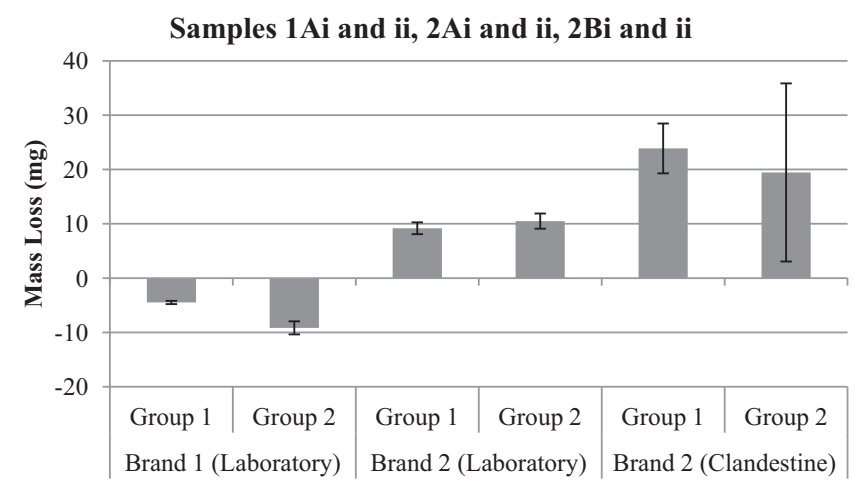

Fig. 11. Mass lost from Samples $1 \mathrm{Ai}$ and $\mathrm{ii}, 2 \mathrm{Ai}$ and $\mathrm{ii}$, and $2 \mathrm{Bi}$ and ii, following 32 weeks of storage. Group 1 opened periodically for sampling over the 32 week aging period; Group 2 stored without opening. All Group 1 samples (1 Ai, 2Ai, and 2Bi) were exposed to dry air. All Group 2 samples (1Aii, 2Aii, and 2Bii) were stored at ambient temperatures.

Examining data from both purification methods (i.e. Brand 1 vs. Brand 2), it is evident that this step in the synthesis protocol had a significant effect on decomposition as can be seen from the vast difference between both vapor profiles and mass lost from the bulk material. By comparison, the type of starting products (i.e. laboratory (Sample 2Ai-dry) vs. clandestine (Samples 2Bi-dry)) had only a minor effect on the vapor profile, although there was a reasonable difference between mass lost. Overall variations due to starting ingredients, however, were negligible in comparison to that of purification methods.

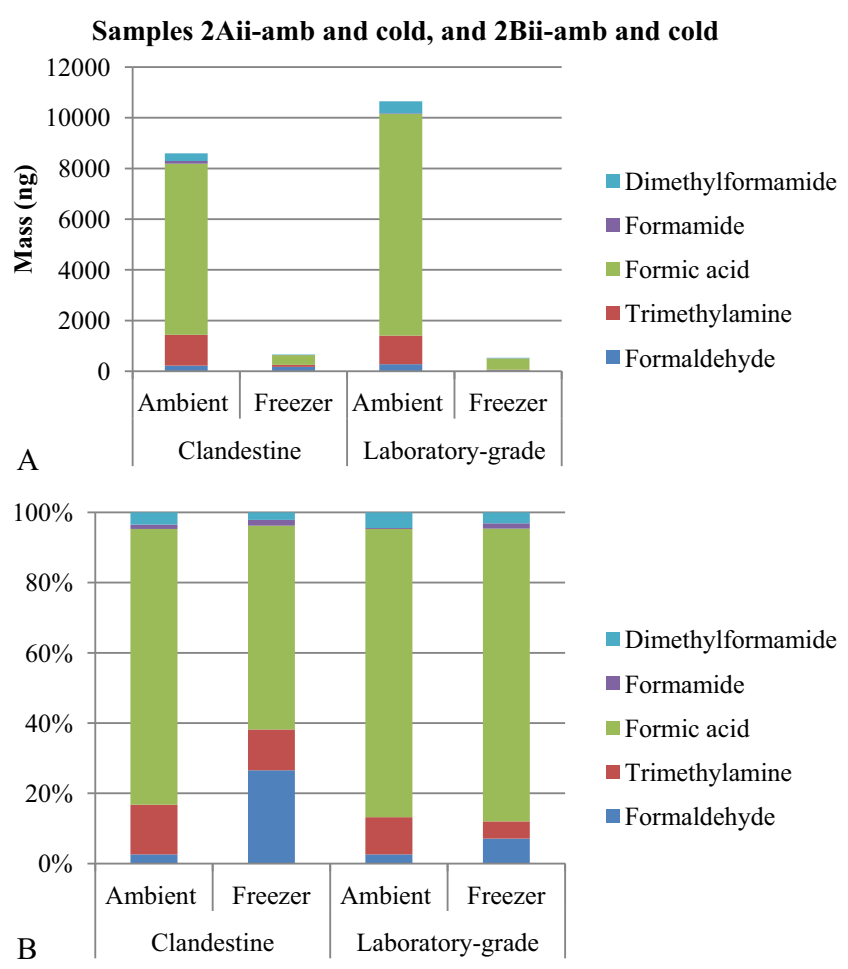

Fig. 12. A. Mass of analyte collected from the headspace of Samples 2Aii-amb and cold and 2Bii-amb and cold (Brand 2, laboratory-grade and clandestine, Group 2) aged 32 weeks under ambient or freezer temperatures; B. mass normalized to total (i.e. vapor profile). 


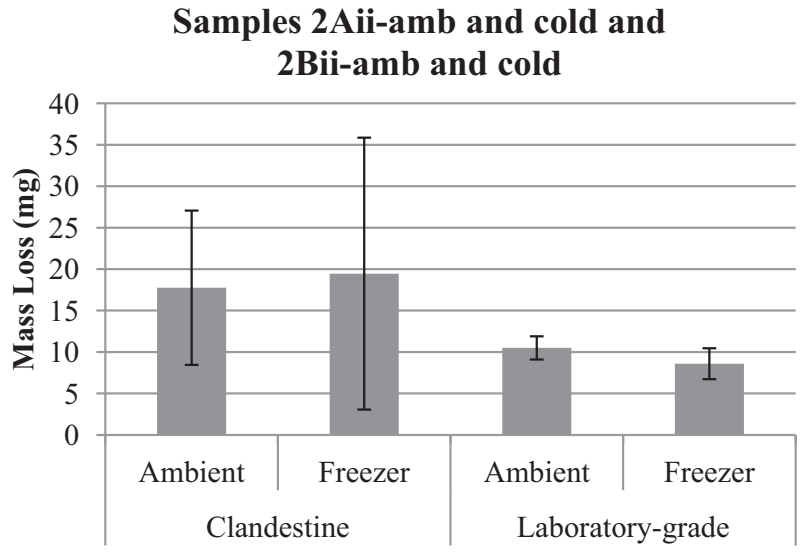

Fig. 13. Mass loss from Samples 2 Aii-amb and cold and 2Bii-amb and cold, following 32 weeks of storage under ambient or freezer temperatures.

\subsection{Humidity}

Following sampling and immediately before storage, all Group 1 samples were exposed to either humidified air or dried air. Decomposition of the HMTD samples and evolution of degradation VOCs were compared across these two variables. The VOCs in the headspace of the Brand 2,laboratory-grade (Samples 2Ai-dry and -humid) samples remained similar in quality and quantity until week 12. At this time there was an increase in both formamide species when samples were exposed to humidified air (Fig. 7). The difference persisted throughout the rest of the sampling period, becoming more prominent with the dimethylformamide. This can also be seen to some extent in the Brand 1 samples (Samples 1Ai-dry and -humid), with dimethylformamide being detected at weeks 2,4 , and 12 in the humidified samples only, and a small increase in the amount of dimethylfomamide at weeks 24-32 (Fig. 8). A significantly higher amount of trimethylamine was produced in the humidified samples compared to the dried samples in Brand 1. This trend was not seen in Brand 2. The humidification of the samples did not alter the quantity of any other species in the headspace, nor were unique VOCs formed. There was also no significant difference in the amount of mass lost between the samples, for any formulation, including Samples $1 \mathrm{Ai}, 2 \mathrm{Ai}$, and $2 \mathrm{Bi}$ (Fig. 9). Thus, humidity had some effect on the VOC profile of the samples, but did not have an effect on the overall rate of decomposition.

\subsection{Sampling frequency}

All samples discussed previously were from Group 1, sampled frequently over a period of 32 weeks. Group 2, a control group, was not sampled frequently. It was sampled and weighed solely upon receipt and again at the end of the study. Headspace and gravimetric analysis revealed that both Groups 1 and 2, for all formulations (Samples $1 \mathrm{Ai}$ and ii, 2Ai and ii, 2Bi and ii), presented similar VOC profiles (Fig. 10A) and lost similar amounts of material by mass (Fig. 11) after 32 weeks. Both Groups 1 and 2 of Brand 1 (Samples $1 \mathrm{Ai}$ and 1Aii) gained small amounts of mass. Again, this can likely be attributed to sequestration of water upon opening and throughout the time of analysis. Though the VOC profiles were similar (Fig. 10A), the total quantity of volatiles collected (Fig. 10B) was significantly higher in the across all stored samples (Group 2)., indicating that the Group 1 samples were not yet at equilibrium at each time of analysis (i.e. after two weeks between analyses). Overall, neither storage condition prevented or accelerated decomposition for any formulation of HMTD.

\subsection{Storage temperature}

Group 2, the stored samples, were further split into two sets (Samples 2Aii-amb and -cold, and 2Bii-amb and -cold). One set was stored under laboratory ambient temperature, as discussed above, while the second set was stored in a freezer at $-4^{\circ} \mathrm{C}$. This comparison was only made for Brand 2, both clandestine and laboratory-grade samples. The headspace components and mass loss were measured upon reception and following the 32 weeks storage period. For both laboratory-grade (Samples 2Aii) and clandestine samples (Samples $2 \mathrm{Bii}$ ), there was a significant difference in the total amount of VOCs collected between the ambient and freezer samples (Fig. 12A); however, the ratios of the VOCs (i.e. vapor profile) in the laboratory-grade samples in both the ambient and frozen samples were similar (Fig. 12B). There was a difference between the ambient and freezer clandestine samples, as the freezer sample had an increased amount of formaldehyde compared to the same sample stored at ambient temperatures. This formaldehyde was likely present from the initial starting product, hexamine, as discussed above, and it is probable that the formaldehyde in the ambient sample evaporated through the parafilmed cap and therefore was not observed.

The mass losses over the sampling period were statistically similar ( $t$-test, 95\% confidence) between the ambient and freezer samples for both clandestine and laboratory-grade material (Samples 2Aii-amb and -cold, and 2Bii-amb and-cold; Fig. 13). Like other samples, there was greater mass loss in the clandestine samples compared to the laboratory samples, although this difference was not statistically significant ( $t$-test, $95 \%$ confidence), due to the great variation in mass loss for the clandestine samples.

\subsection{Determination of vapor concentration}

The vapor concentration of the decomposition VOCs was estimated by comparison to vapor calibration curves for formic acid, dimethylformamide, and trimethylamine. The calibration curves were collected using permeation tubes with the vapor concentration calculated based on the permeation rates measured by the manufacturer. Results, seen in Table 4, represent the averaged vapor concentration of each sample after 32 days of sampling. Formic acid had the greatest headspace concentration, averaging $40 \mathrm{ppb}$, while most of the other compounds barely exceeded

Table 4

Estimated headspace concentration ( $\mathrm{ppb}$ in $\mu \mathrm{g} / \mathrm{L}_{\mathrm{air}}$ ) of analytes in the headspace of bulk HMTD. "Estimated using dimethylformamide calibration curve.

\begin{tabular}{|c|c|c|c|c|c|c|}
\hline & \multicolumn{6}{|c|}{ Estimated Headspace Concentration (ppb) } \\
\hline & \multicolumn{2}{|c|}{ Formic Acid } & \multicolumn{2}{|c|}{ Dimethylformamide } & \multicolumn{2}{|c|}{ Trimethylamine } \\
\hline & Dry Air & Humid Air & Dry Air & Humid Air & Dry Air & Humid Air \\
\hline Samples $1 \mathrm{Ai}$ & 23.5 & 19.5 & 2.07 & 2.48 & & \\
\hline Samples 2Ai & 47.2 & 77.4 & 3.72 & 7.93 & 2.92 & 2.83 \\
\hline Samples 2Bi & 26.2 & 50.3 & 1.59 & 4.83 & 0.199 & 2.99 \\
\hline
\end{tabular}


5 ppb. In both Brands 1 and 2, formic acid made up between 86$92 \%$ of the vapor mixture composition.

\section{Discussion}

In agreement with Oxley et. al. [24] and Steinkamp et al. [25], molecular HMTD vapor was not observed using the methods employed in the course of this study; however, a variety of volatile decomposition products with vapor concentrations estimated in the ppb range were detected. Based on previous work, it was predicted that humidity would have the greatest effect on decomposition as water has been shown to facilitate the decomposition of HMTD. Water from humidity did have some effect on the longterm decomposition of the HMTD material examined in this study, as shown by the increase in several VOCs in the humidified samples, but it did not have the profound effect expected.

Sampling frequency (i.e. frequency of exposure to ambient air) and storage temperature (ambient and $-4{ }^{\circ} \mathrm{C}$ ) were two other variables considered for HMTD decomposition. Data showed that these parameters had little effect on the decomposition over the duration of this study. The vapor profiles and mass change showed little variation with either sampling frequency or storage temperature. The only change was in the total amount of VOCs measured.

The synthesis method (i.e. Brand 1 vs. Brand 2) did have a profound effect on both the vapor profile and mass, however. The crucial difference between the synthesis methods was drying by methanol. Brand 1 was washed with water, and then dried with methanol, while Brand 2 was solely washed with water following the synthesis. The material that was dried with methanol degraded slowly, as shown by its minimal mass loss and low levels of volatile components in the headspace, while the material that was not dried degraded rapidly from receipt. This observation is in agreement with Oxley et. al. and Steinkamp et. al. [25,24].

Brand 1, the methanol-dried material, showed a great evolution of formic acid in the headspace after aging for 18 weeks. Gravimetric analysis indicated that this material did likely acquire some water at the time of analysis, prior to the presence of formic acid, as is postulated by the increase in mass of the samples. The added water could have driven the initial formation of formic acid seen at week 18. The presence of formic acid in the headspace of the enclosed sample could then have further propagated the HMTD decomposition reaction to form additional formic acid. Oxley et. al. had indicated that residual citric acid can destabilize HMTD [24]. It is presumed that formic acid would have a similar effect. For comparison, Brand 2, which was not methanol-dried, had water present from the start, and decomposition thus proceeded rapidly.

Overall, across all variables, formic acid was the most abundant decomposition product in the headspace. Formaldehyde was also significant to the vapor profile as it was detected at nearly every sampling across all variables. As detection of HMTD vapor in a field sampling environment would be improbable, it is suggested that vapor detection capabilities focus on the detection of these compounds, in addition to trimethylamine and dimethylformamide. Further research should also be carried out exploring the effects of other purification methods, such as recrystallization.

\section{Conclusion}

The decomposition of HMTD was monitored over 32 weeks across a number of variables including synthesis ingredients and method, storage conditions, and environment. By comparing vapor profiles across these variables, potential key components from HMTD decomposition were identified. These included formic acid and formaldehyde. Other important decomposition products detected include trimethylamine, dimethylformamide, formamide, and acetic acid. It was also determined that the choice of purification (i.e. rinsing) method had a much greater effect on overall vapor profile when compared to all other variables.

\section{Acknowledgements}

The authors would like to thank the Federal Bureau of Investigations, Explosive Unit, and Tripwire Operations for supplying the explosives used in this study. The authors would also like to acknowledge Lucus Steinkamp, Kevin Johnson, and Braden Giordano for their input and assistance throughout this research.

Funding: This work was supported by the U.S. Department of Homeland Security, Science and Technology Directorate, Homeland Security Advanced Research Projects Agency, Explosives Division, and the U.S. Naval Research Laboratory through the Jerome and Isabella Karle Distinguished Scholar Fellowship.

\section{Appendix A. Supplementary data}

Supplementary data associated with this article can be found, in the online version, at http://dx.doi.org/10.1016/j.forc.2017.03.001.

\section{References}

[1] H. Ostmark, A. Wallin, H. Ang, Vapor pressure of explosives: a critical review, Propellants Explos. Pyrotech. 37 (2012) 12-23.

[2] A.I. Fountain, S. Christesen, R. Moon, J. Guicheteau, Recent advances and remaining challenges for spectroscopic detection of explosives threats, Appl. Spectrosc. OA. 68 (2014) 795-811.

[3] Z. Li, W. Basset, J. Askim, K. Suslick, Differentiation among peroxide explosives with an optoelectronic nose, Chem. Commun. 51 (2015) 15312-15315.

[4] C. Taylor, W. Rinkenbach, HMTD - a new detonating explosive, Army Ordnance 5 (1924) 463-466.

[5] The Federal Bureau of Investigation, Famous cases and criminals: Millennium plot/Ahmed Ressam. <https://www.fbi.gov/history/famous-cases/millenniumplot-ahmed-ressam>, 2012 (accessed 20.05.16).

[6] D. Gardam, 'We've never seen a bomb like 21/7 devices', 11 July 2007. < http:// www.telegraph.co.uk/news/uknews/1557106/Weve-never-seen-a-bomb-like217-devices.html>, 2007 (accessed 20.05.16).

[7] C. Chiver, Quantity of explosive found in Belgium surprises officials. <http:// www.nytimes.com/2016/03/24/world/europe/brussels-explosives-tatp.html? $r=0>, 2016$ (accessed 20.05.16).

[8] Fox News [online], FBI works to counter kitchen sink bomb, <http./ www.foxnews.com/story/2007/02/18/fbi-works-to-counter-kitchen-sinkbomb.html>, 2007 (accessed 20.05.16).

[9] J. Yinon, Field detection and monitoring of explosives, TrAC Trends Anal. Chem. 21 (2002) 292-301.

[10] D. Moore, Instrumentation for trace detection of high explosives, Rev. Sci. Instrum. 75 (2004) 2499.

[11] J. Kozole, J. Tomlinson-Phillips, J.R. Stairs, J.D. Harpe, S. Lukow, R. Lareau, $H$ Boudries, H. Lai, C.S. Brauer, Characterizing the gas phase ion chemistry of an ion trap mobility spectrometry based explosive trace detector using a tandem mass spectrometer, Talanta 99 (2012) 799-810.

[12] S. Singh, Sensors - an effective approach for the detection of explosives, J. Hazard. Mater. 144 (2007) 15-28.

[13] K.G. Furton, L.J. Myers, The scientific foundation and efficacy of the use of canines as chemical detectors for explosives, Talanta 54 (2001) 487-500.

[14] R.G. Ewing, M.J. Waltman, D.A. Atkinson, J.W. Grate, The vapor pressure of explosives, TrAC Trends Anal. Chem. 42 (2013) 35-48.

[15] P. Damour, A. Freedman, J. Wormhoudt, Knudsen effusion measurement of organic peroxide vapor pressures, Propellants Explos. Pyrotech. 32 (2010) 514-520.

[16] J.C. Oxley, J.L. Smith, W. Luo, J. Brady, Determining the vapor pressures of diacetone diperoxide (DADP) and hexamethylene triperoxide diamine (HMTD), Propellants Explos. Pyrotech. 34 (2009) 539-543.

[17] B.C. Giordano, A.L. Lubrano, C.R. Field, G.E. Collins, Dynamic headspace generation and quantitation of triacetone triperoxide vapor, J. Chromatogr A 1331 (2014) (2014) 38-43.

[18] R. Schulte-Ladbeck, U. Karst, Determination of triacetonetriperoxide in ambient air, Anal. Chim. Acta 482 (2003) 183-188.

[19] J. C. Oxely, J. L. Smith, J. Moran, K. Nelson, W. E. Utley, Training dogs to detect triacetone triperoxide (TATP), in Proceedings of SPIE; Sensors, and Command, Control, Communications, and Intelligence Technologies for Homeland Security and Homeland Defense III, Bellingham, WA, 2004.

[20] E. Capua, R. Cao, C.N. Sukenik, R. Naaman, Detection of triacetone triperoxide (TATP) with an array of sensors based on on-specific interactions, Sens. Actuators B: Chem. 140 (2009) 122-127. 
[21] W. Schaefer, J. Fourkas, B. Tiemann, Structure of hexamethylene triperoxide diamine, J. Am. Chem. Soc. 107 (1985) 2461-2463.

[22] J. Oxley, J. Smith, H. Chen, E. Cioffi, Decomposition of multi-peroxidic compounds. Part II. Hexamethylene triperoxide diamine (HMTD), Thermochim. Acta 388 (2002) 215-225.

[23] W.P. Schaefer, J.T. Forukas, B.G. Tiemann, Structure of hexamethylene triperoxide diamine, J. Am. Chem. Soc. 107 (1985) 2461-2463.

[24] J.C. Oxley, J.L. Smith, M. Porter, L. McLennan, K. Colizza, Y. Zeiri, R. Kosloff, F. Dubnikova, Synthesis and degradation of hexamethylene triperoxide diamine (HMTD), Propellants Explos. Pyrotech. 40 (2015) 1-18.
[25] F.L. Steinkamp, L.E. DeGreeff, G. Collins, S.L. Rose-Pehrsson, Factors affecting the intramolecular decomposition of hexamethylene triperoxide diamine and implications for detection, J. Chromatogr A 1451 (2016) 83-90.

[26] L. DeGreeff, D.A. Rogers, C. Katilie, K. Johnson, S. Rose-Pehrsson, Technical note: Headspace analysis of explosive compounds using a novel sampling chamber, Forensic Sci. Int. 248 (2015) 55-60. 


\section{Appendix 1.}

Data represent the mass of analyte vapor collected from the headspace of aging bulk HMTD including all formulations and storage condition variables. Values are listed as averages followed by the value of one standard deviation.

Table 1. Synthesis method - Brand 1 (Group 1); Synthesis ingredients - Laboratory-grade; Storage - Dried at ambient.

\begin{tabular}{|c|c|c|c|c|c|c|c|c|}
\hline \multirow[b]{2}{*}{$\begin{array}{l}\text { Age of } \\
\text { sample }\end{array}$} & \multicolumn{6}{|c|}{ Headspace compound (ng) } & \multirow[b]{2}{*}{ Sum } & \multirow[b]{2}{*}{ Stdev } \\
\hline & Formaldehyde & Acetic acid & Formic acid & Formamide & $\begin{array}{l}\text { Dimethyl } \\
\text { formamide }\end{array}$ & $\begin{array}{l}\text { Trimethyl } \\
\text { amine }\end{array}$ & & \\
\hline Week 0 & $7.24( \pm .56)$ & & & & & & 7.2 & 0.56 \\
\hline Week 2 & $5.28( \pm 0.46)$ & & & & & $5.57( \pm 4.87)$ & 10.8 & 5.33 \\
\hline Week 4 & $3.45( \pm 1.14)$ & & & & & $9.02( \pm 0.15)$ & 12.5 & 1.3 \\
\hline Week 6 & Below LOD & & & & & Below LOD & nd & \\
\hline Week 8 & Below LOD & & & & & $6.23( \pm 1.01)$ & 6.23 & 1.01 \\
\hline Week 10 & Below LOD & & & & & & nd & \\
\hline Week 12 & $9.01( \pm 0.30)$ & & & & & & 9.01 & 0.30 \\
\hline Week 14 & $2.56( \pm 1.16)$ & & & & & & 2.56 & 1.16 \\
\hline Week 16 & $1.46( \pm 0.91)$ & & & & & & 1.46 & 0.91 \\
\hline Week 18 & & & $423( \pm 51)$ & & & & 423 & 51 \\
\hline Week 20 & & & $1510( \pm 520)$ & & & & 1510 & 520 \\
\hline Week 22 & & & $2030( \pm 380)$ & & & & 2030 & 380 \\
\hline Week 24 & & & $1400( \pm 530)$ & & $3.52( \pm 0.41)$ & & 1400 & 530 \\
\hline Week 28 & & & $3710( \pm 70)$ & & $5.55( \pm 0.53)$ & & 3710 & 70 \\
\hline Week 32 & & & $3250( \pm 810)$ & & $8.98( \pm 0.90)$ & & 3260 & 810 \\
\hline
\end{tabular}


Table 2. Synthesis method - Brand 1 (Group1); Synthesis ingredients - Laboratory-grade; Storage - Humidified at ambient.

\begin{tabular}{|c|c|c|c|c|c|c|c|c|}
\hline \multirow[b]{2}{*}{$\begin{array}{l}\text { Age of } \\
\text { sample }\end{array}$} & \multicolumn{6}{|c|}{ Headspace compound (ng) } & \multirow[b]{2}{*}{ Sum } & \multirow[b]{2}{*}{ Stdev } \\
\hline & Formaldehyde & Acetic acid & Formic acid & Formamide & $\begin{array}{l}\text { Dimethyl } \\
\text { formamide }\end{array}$ & $\begin{array}{l}\text { Trimethyl } \\
\text { amine }\end{array}$ & & \\
\hline Week 0 & $11.5( \pm 6.3)$ & & & & & $3.76( \pm 3.26)$ & 15.3 & 9.6 \\
\hline Week 2 & $10.9( \pm 4.2)$ & & & & $8.91( \pm 0.61)$ & $18.4( \pm 9.8)$ & 38.2 & 14.6 \\
\hline Week 4 & $2.57( \pm 0.56)$ & & & & $9.15( \pm 1.22)$ & $16.8( \pm 9.7)$ & 28.5 & $\mathbf{1 1 . 5}$ \\
\hline Week 6 & & & & & & $6.17( \pm 0.23)$ & 6.17 & 0.23 \\
\hline Week 8 & $5.16( \pm 3.14)$ & & & & & $18.1( \pm 9.7)$ & 23.3 & 12.8 \\
\hline Week 10 & & & & & & & nd & \\
\hline Week 12 & $9.78( \pm 0.91)$ & & & & $8.76( \pm 0.09)$ & $19.1( \pm 12.4)$ & 37.7 & $\mathbf{1 3 . 4}$ \\
\hline Week 14 & $1.65( \pm 0.99)$ & & & & & & 1.65 & 0.99 \\
\hline Week 16 & $1.49( \pm 0.74)$ & & & & & & 1.49 & 0.74 \\
\hline Week 18 & & & & & & & nd & \\
\hline Week 20 & & & $691( \pm 308)$ & & & & 691 & 308 \\
\hline Week 22 & & & $1770( \pm 270)$ & & & & 1770 & 270 \\
\hline Week 24 & & & $\begin{array}{c}2940( \pm \\
2250) \\
\end{array}$ & & $4.90( \pm 0.15)$ & & 2950 & 2250 \\
\hline Week 28 & & & $\begin{array}{c}4390( \pm \\
2850) \\
\end{array}$ & & $8.79( \pm 3.26)$ & $6.91( \pm 2.76)$ & 4410 & 2860 \\
\hline Week 32 & & & $\begin{array}{c}8320( \pm \\
2080) \\
\end{array}$ & & $10.2( \pm 1.0)$ & $8.40( \pm 2.52)$ & 8340 & 2080 \\
\hline
\end{tabular}

Table 3. Synthesis method - Brand 2 (Group 1); Synthesis ingredients - Laboratory-grade; Storage - Dried at ambient.

\begin{tabular}{|c|c|c|c|c|c|c|c|c|}
\hline \multirow[b]{2}{*}{$\begin{array}{l}\text { Age of } \\
\text { sample }\end{array}$} & \multicolumn{6}{|c|}{ Headspace compound (ng } & \multirow[b]{2}{*}{ Sum } & \multirow[b]{2}{*}{ Stdev } \\
\hline & Formaldehyde & Acetic acid & Formic acid & Formamide & $\begin{array}{l}\text { Dimethyl } \\
\text { formamide }\end{array}$ & $\begin{array}{l}\text { Trimethyl } \\
\text { amine }\end{array}$ & & \\
\hline Week 0 & $119( \pm 6)$ & $55.0( \pm 29.0)$ & $440( \pm 56)$ & & & & 618 & 93 \\
\hline Week 2 & $119( \pm 31)$ & $19.1( \pm 0.7)$ & $712( \pm 174)$ & $2.62( \pm 0.59)$ & $3.29( \pm 0.13)$ & & 856 & 206 \\
\hline Week 4 & $104( \pm 39)$ & $28.5( \pm 3.7)$ & $678( \pm 208)$ & $7.08( \pm 0.85)$ & $8.34( \pm 1.02)$ & & 834 & 250 \\
\hline Week 6 & $42.0( \pm 0.7)$ & $17.3( \pm 0.2)$ & $934( \pm 141)$ & $8.51( \pm 0.64)$ & $8.79( \pm 0.47)$ & & 1010 & 140 \\
\hline Week 8 & $135( \pm 20)$ & $26.2( \pm 1.0)$ & $2210( \pm 700)$ & $14.5( \pm 1.5)$ & $22.6( \pm 1.3)$ & & 2280 & 700 \\
\hline Week 10 & $159( \pm 98)$ & $36.7( \pm 5.9)$ & $\begin{array}{c}4270( \pm \\
1660) \\
\end{array}$ & $12.8( \pm 2.3)$ & $37.3( \pm 2.3)$ & & 4520 & 1780 \\
\hline Week 12 & $46.7( \pm 22.3)$ & $29.8( \pm 0.9)$ & $2210( \pm 160)$ & $10.3( \pm 0.5)$ & $11.5( \pm 6.6)$ & $1.46( \pm 0.13)$ & 2310 & 190 \\
\hline Week 14 & $8.55( \pm 10.5)$ & $27.0( \pm 1.2)$ & $\begin{array}{c}2160( \pm \\
1330) \\
\end{array}$ & $10.0( \pm 0.9)$ & $21.5( \pm 4.8)$ & $4.80( \pm 0.03)$ & 2230 & 1350 \\
\hline Week 16 & $252( \pm 49)$ & & $2060( \pm 300)$ & $25.6( \pm 4.9)$ & $89.5( \pm 8.8)$ & $10.8( \pm 1.5)$ & 2440 & 360 \\
\hline Week 18 & $206( \pm 114)$ & & $1960( \pm 900)$ & $55.7( \pm 10.0)$ & $151( \pm 86)$ & $85.8( \pm 17.8)$ & 2460 & 1130 \\
\hline Week 20 & $103( \pm 21)$ & & $2590( \pm 190)$ & $57.1( \pm 5.8)$ & $116( \pm 7)$ & $67.5( \pm 12.7)$ & 2940 & 230 \\
\hline Week 22 & $226( \pm 20)$ & & $2220( \pm 140)$ & $18.5( \pm 1.3)$ & $64.4( \pm 16.3)$ & $96.0( \pm 18.0)$ & 2630 & 270 \\
\hline Week 24 & $264( \pm 108)$ & & $1830( \pm 400)$ & $15.5( \pm 6.5)$ & $45.1( \pm 17.3)$ & $125( \pm 53)$ & 2280 & 580 \\
\hline Week 28 & $195( \pm 16)$ & & $3850( \pm 790)$ & $28.3( \pm 7.8)$ & $89.7( \pm 15.7)$ & $232( \pm 68.4)$ & 4400 & 900 \\
\hline Week 32 & $222( \pm 66)$ & & $3220( \pm 430)$ & $28.9( \pm 7.5)$ & $124( \pm 20)$ & $328( \pm 43)$ & 3920 & 560 \\
\hline
\end{tabular}


Table 4 . Synthesis method - Brand 2 (Group 1); Synthesis ingredients - Laboratory-grade; Storage - Humidified at ambient.

\begin{tabular}{|c|c|c|c|c|c|c|c|c|}
\hline \multirow[b]{2}{*}{$\begin{array}{l}\text { Age of } \\
\text { sample }\end{array}$} & \multicolumn{6}{|c|}{ Headspace compound (ng) } & \multirow[b]{2}{*}{ Sum } & \multirow[b]{2}{*}{ Stdev } \\
\hline & Formaldehyde & Acetic acid & Formic acid & Formamide & $\begin{array}{l}\text { Dimethyl } \\
\text { formamide }\end{array}$ & $\begin{array}{l}\text { Trimethyl } \\
\text { amine }\end{array}$ & & \\
\hline Week 0 & $127( \pm 14)$ & $25.7( \pm 1.2)$ & $375( \pm 78)$ & & & & 528 & 93 \\
\hline Week 2 & $127( \pm 55)$ & $22.0( \pm 2.5)$ & $474( \pm 96)$ & $4.21( \pm 0.68)$ & $5.60( \pm 0.59)$ & & 633 & 156 \\
\hline Week 4 & $97.9( \pm 37.4)$ & $33.5( \pm 0.4)$ & $814( \pm 212)$ & $8.22( \pm 0.81)$ & $15.2( \pm 1.9)$ & & 968 & 252 \\
\hline Week 6 & $88.8( \pm 1.5)$ & $25.8( \pm 1.9)$ & $1870( \pm 830)$ & $13.3( \pm 2.6)$ & $22.5( \pm 0.6)$ & & 2020 & 840 \\
\hline Week 8 & $93.2( \pm 46.6)$ & $28.1( \pm 2.6)$ & $1790( \pm 630)$ & $17.3( \pm 2.3)$ & $39.7( \pm 9.0)$ & & 1970 & 690 \\
\hline Week 10 & $142( \pm 13)$ & $45.4( \pm 2.3)$ & $\begin{array}{c}5570( \pm \\
2640) \\
\end{array}$ & $20.8( \pm 3.9)$ & $72.7( \pm 10.0)$ & & 5850 & 2670 \\
\hline Week 12 & $44.1( \pm 14.7)$ & $32.8( \pm 1.0)$ & $2720( \pm 180)$ & $12.3( \pm 1.0)$ & $37.3( \pm 6.6)$ & $1.42( \pm 0.09)$ & 2850 & 200 \\
\hline Week 16 & $361( \pm 195)$ & & $\begin{array}{c}4010( \pm \\
2170) \\
\end{array}$ & $41.8( \pm 11.3)$ & $272( \pm 39)$ & $10.8( \pm 2.0)$ & 4700 & 2420 \\
\hline Week 18 & $197( \pm 86)$ & & $2710( \pm 980)$ & $66.7( \pm 19.3)$ & $400( \pm 135)$ & $63.5( \pm 19.4)$ & 3440 & 1240 \\
\hline Week 20 & $235( \pm 34)$ & & $\begin{array}{c}6250( \pm \\
2070)\end{array}$ & $103( \pm 16)$ & $443( \pm 62)$ & $91.3( \pm 22.7)$ & 7120 & 2200 \\
\hline Week 22 & $253( \pm 131)$ & & $3360( \pm 570)$ & $26.5( \pm 4.3)$ & $183( \pm 65)$ & $118( \pm 40)$ & 3710 & 810 \\
\hline Week 24 & $208( \pm 108)$ & & $2010( \pm 110)$ & $18.1( \pm 6.4)$ & $108( \pm 14)$ & $83.1( \pm 15.3)$ & 2430 & 250 \\
\hline Week 28 & $144( \pm 75)$ & & $3230( \pm 910)$ & $25.5( \pm 6.5)$ & $89.7( \pm 15.7)$ & $232( \pm 68.4)$ & 3720 & 1080 \\
\hline Week 32 & $222( \pm 66)$ & & $3220( \pm 430)$ & $28.9( \pm 7.5)$ & $153( \pm 43)$ & $122( \pm 20)$ & 3740 & 570 \\
\hline
\end{tabular}

Table 5. Synthesis method - Brand 2 (Group 1); Synthesis ingredients - Clandestine; Storage - Dried at ambient.

\begin{tabular}{|c|c|c|c|c|c|c|c|c|}
\hline \multirow[b]{2}{*}{$\begin{array}{l}\text { Age of } \\
\text { sample }\end{array}$} & \multicolumn{6}{|c|}{ Headspace compound (ng) } & \multirow[b]{2}{*}{ Sum } & \multirow[b]{2}{*}{ Stdev } \\
\hline & Formaldehyde & Acetic acid & Formic acid & Formamide & $\begin{array}{c}\text { Dimethyl } \\
\text { formamide }\end{array}$ & $\begin{array}{c}\text { Trimethyl } \\
\text { amine }\end{array}$ & & \\
\hline Week 0 & $1020( \pm 20)$ & $49.7( \pm 12.5)$ & $329( \pm 78)$ & & & & 1400 & 110 \\
\hline Week 2 & $149( \pm 94)$ & $19.5( \pm 7.3)$ & $813( \pm 216)$ & $3.73( \pm 0.07)$ & $5.94( \pm 1.48)$ & $3.83( \pm 1.07)$ & 995 & 320 \\
\hline Week 4 & $127( \pm 49)$ & $28.6( \pm 1.0)$ & $695( \pm 69)$ & $8.04( \pm 0.47)$ & $10.8( \pm 1.1)$ & $9.61( \pm 0.87)$ & 881 & 121 \\
\hline Week 6 & $74.0( \pm 34.3)$ & $17.5( \pm 1.07)$ & $877( \pm 309)$ & $8.87( \pm 0.44)$ & $7.29( \pm 0.67)$ & $3.53( \pm 0.27)$ & 988 & 346 \\
\hline Week 8 & $163( \pm 103)$ & $29.2( \pm 4.1)$ & $1270( \pm 300)$ & $14.1( \pm 1.6)$ & $21.6( \pm 3.6)$ & $4.64( \pm 0.58)$ & 1510 & 410 \\
\hline Week 10 & $134( \pm 67)$ & $37.1( \pm 1.7)$ & $2200( \pm 870)$ & $15.4( \pm 2.6)$ & $25.1( \pm 1.8)$ & $5.96( \pm 1.26)$ & 2410 & 940 \\
\hline Week 12 & $28.9( \pm 8.8)$ & $29.8( \pm 0.9)$ & $1350( \pm 65)$ & $9.96( \pm 1.12)$ & $16.3( \pm 1.5)$ & $3.90( \pm 0.59)$ & 1440 & 80 \\
\hline Week 14 & $12.0( \pm 4.2)$ & $27.3( \pm 0.5)$ & $1020( \pm 400)$ & $8.95( \pm 0.95)$ & $16.2( \pm 1.9)$ & $4.09( \pm 1.10)$ & 1090 & 410 \\
\hline Week 16 & $376( \pm 71)$ & & $2360( \pm 940)$ & $28.4( \pm 13.1)$ & $96.7( \pm 25.7)$ & $8.90( \pm 2.27)$ & 2870 & 1050 \\
\hline Week 18 & $132( \pm 110)$ & & $1250( \pm 740)$ & $41.4( \pm 29.9)$ & $94.5( \pm 29.4)$ & $74.2( \pm 20.9)$ & 1590 & 930 \\
\hline Week 20 & $92.1( \pm 32.2)$ & & $1750( \pm 600)$ & $48.2( \pm 2.0)$ & $96.5( \pm 19.0)$ & $82.6( \pm 10.3)$ & 2070 & 670 \\
\hline Week 22 & $171( \pm 20)$ & & $1490( \pm 160)$ & $19.8( \pm 1.4)$ & $39.1( \pm 4.2)$ & $106( \pm 29)$ & 1830 & 220 \\
\hline Week 24 & $193( \pm 78)$ & & $1610( \pm 431)$ & $17.5( \pm 9.3)$ & $31.7( \pm 14.5)$ & $113( \pm 40)$ & 1970 & 580 \\
\hline Week 28 & $109( \pm 41)$ & & $2150( \pm 930)$ & $20.8( \pm 8.0)$ & $40.9( \pm 8.6)$ & $234( \pm 105)$ & 2560 & 1100 \\
\hline Week 32 & $98.8( \pm 33.4)$ & & $1830( \pm 310)$ & $22.1( \pm 2.7)$ & $56.5( \pm 8.2)$ & $247( \pm 54)$ & 2270 & 410 \\
\hline
\end{tabular}


Table 6. Synthesis method - Brand 2 (Group 1); Synthesis ingredients - Clandestine; Storage - Humidified at ambient.

\begin{tabular}{|c|c|c|c|c|c|c|c|c|}
\hline \multirow[b]{2}{*}{$\begin{array}{l}\text { Age of } \\
\text { sample }\end{array}$} & \multicolumn{6}{|c|}{ Headspace compound (ng) } & \multirow[b]{2}{*}{ Sum } & \multirow[b]{2}{*}{ Stdev } \\
\hline & Formaldehyde & Acetic acid & Formic acid & Formamide & $\begin{array}{l}\text { Dimethyl } \\
\text { formamide }\end{array}$ & $\begin{array}{l}\text { Trimethyl } \\
\text { amine }\end{array}$ & & \\
\hline Week 0 & $191( \pm 23)$ & $33.7( \pm 0.7)$ & $491( \pm 75)$ & & & & 717 & 98 \\
\hline Week 2 & $285( \pm 80)$ & $38.3( \pm 5.8)$ & $712( \pm 221)$ & $5.53( \pm 1.54)$ & $14.0( \pm 1.5)$ & $7.38( \pm 1.96)$ & 1060 & 310 \\
\hline Week 4 & $140( \pm 55)$ & $33.4( \pm 1.3)$ & $552( \pm 170)$ & $8.86( \pm 1.00)$ & $19.3( \pm 5.9)$ & $10.5( \pm 0.95)$ & 764 & 234 \\
\hline Week 6 & $61.1( \pm 18.6)$ & $21.2( \pm 4.1)$ & $659( \pm 372)$ & $9.01( \pm 1.49)$ & $18.8( \pm 0.6)$ & $4.63( \pm 0.21)$ & 774 & 397 \\
\hline Week 8 & $109( \pm 51)$ & $36.3( \pm 10.3)$ & $1300( \pm 950)$ & $15.8( \pm 6.5)$ & $38.5( \pm 9.3)$ & $3.83( \pm 0.08)$ & 1500 & 1020 \\
\hline Week 10 & $141( \pm 10)$ & $47.8( \pm 12.8)$ & $\begin{array}{c}2480( \pm \\
1300) \\
\end{array}$ & $15.3( \pm 0.2)$ & $48.5( \pm 0.2)$ & $3.84( \pm 1.15)$ & 2740 & 1320 \\
\hline Week 12 & $26.6( \pm 3.6)$ & $36.2( \pm 0.3)$ & $1630( \pm 300)$ & $10.2( \pm 0.4)$ & $35.6( \pm 2.2)$ & $3.63( \pm 1.01)$ & 1750 & 300 \\
\hline Week 14 & $20.7( \pm 10.4)$ & $34.5( \pm 5.2)$ & $1800( \pm 460)$ & $11.1( \pm 1.0)$ & $44.7( \pm 16.8)$ & $6.93( \pm 1.40)$ & 1920 & 500 \\
\hline Week 16 & $413( \pm 33)$ & & $3970( \pm 560)$ & $42.5( \pm 10.1)$ & $327( \pm 34)$ & $15.3( \pm 9.0)$ & 4770 & 650 \\
\hline Week 18 & $166( \pm 109)$ & & $\begin{array}{c}2150( \pm \\
1190) \\
\end{array}$ & $48.6( \pm 9.0)$ & $253( \pm 101)$ & $71.9( \pm 35.5)$ & 2690 & 1440 \\
\hline Week 20 & $88.0( \pm 12.9)$ & & $\begin{array}{c}2440( \pm \\
1220)\end{array}$ & $70.0( \pm 16.3)$ & $265( \pm 62)$ & $118( \pm 12)$ & 2980 & 1330 \\
\hline Week 22 & $193( \pm 76)$ & & $2630( \pm 160)$ & $21.5( \pm 2.2)$ & $114( \pm 29)$ & $89.7( \pm 40.2)$ & 3050 & 310 \\
\hline Week 24 & $183( \pm 73)$ & & $1800( \pm 30)$ & $9.78( \pm 5.46)$ & $77.6( \pm 19.9)$ & $81.9( \pm 5.32)$ & 2140 & 140 \\
\hline Week 28 & $135( \pm 62)$ & & $3600( \pm 740)$ & $24.3( \pm 2.9)$ & $121( \pm 58)$ & $297( \pm 129)$ & 4180 & 1000 \\
\hline Week 32 & $95.2( \pm 52.1)$ & & $3410( \pm 620)$ & $33.9( \pm 10.7)$ & $159( \pm 4.6)$ & $337( \pm 67)$ & 4040 & 750 \\
\hline
\end{tabular}

Table 7. Synthesis method - Brand 1 (Group 2); Synthesis ingredients - Clandestine; Storage - Ambient.

\begin{tabular}{|c|c|c|c|c|c|c|c|c|}
\hline \multirow{2}{*}{$\begin{array}{c}\text { Age of } \\
\text { sample }\end{array}$} & Formaldehyde & Acetic acid & Formic acid & Formamide & $\begin{array}{c}\text { Dimethyl } \\
\text { formamide }\end{array}$ & $\begin{array}{c}\text { Trimethyl } \\
\text { amine }\end{array}$ & \multicolumn{1}{c|}{ Sum } & Stdev \\
\cline { 2 - 9 } & & & & & & $\mathbf{7 . 2 4}$ & $\mathbf{0 . 5 6}$ \\
\hline Week 0 & $7.24( \pm .56)$ & & $\begin{array}{c}6200( \pm \\
3050)\end{array}$ & & $9.21( \pm 1.30)$ & $7.72( \pm 2.32)$ & $\mathbf{6 2 2 0}$ & $\mathbf{3 0 5 0}$ \\
\hline
\end{tabular}

Table 8. Synthesis method - Brand 2 (Group 2); Synthesis ingredients - Laboratory-grade; Storage - Ambient.

\begin{tabular}{|c|c|c|c|c|c|c|c|c|}
\hline \multirow[b]{2}{*}{$\begin{array}{l}\text { Age of } \\
\text { sample }\end{array}$} & \multicolumn{6}{|c|}{ Headspace compound (ng) } & \multirow[b]{2}{*}{ Sum } & \multirow[b]{2}{*}{ Stdev } \\
\hline & Formaldehyde & Acetic acid & Formic acid & Formamide & $\begin{array}{l}\text { Dimethyl } \\
\text { formamide }\end{array}$ & $\begin{array}{l}\text { Trimethyl } \\
\text { amine }\end{array}$ & & \\
\hline Week 0 & $716( \pm 99)$ & $115( \pm 50)$ & $1080( \pm 530)$ & & & & 1910 & 680 \\
\hline Week 32 & $280( \pm 111)$ & & $\begin{array}{c}8740( \pm \\
4410) \\
\end{array}$ & $25.5( \pm 11.0)$ & $475( \pm 210)$ & $1120( \pm 860)$ & 9520 & 5600 \\
\hline
\end{tabular}


Table 9. Synthesis method - Brand 2 (Group 2); Synthesis ingredients - Laboratory-grade; Storage - Freezer.

\begin{tabular}{|c|c|c|c|c|c|c|c|c|}
\hline \multirow[b]{2}{*}{$\begin{array}{l}\text { Age of } \\
\text { sample }\end{array}$} & \multicolumn{6}{|c|}{ Headspace compound (ng) } & \multirow[b]{2}{*}{ Sum } & \multirow[b]{2}{*}{ Stdev } \\
\hline & Formaldehyde & Acetic acid & Formic acid & Formamide & $\begin{array}{l}\text { Dimethyl } \\
\text { formamide }\end{array}$ & $\begin{array}{l}\text { Trimethyl } \\
\text { amine }\end{array}$ & & \\
\hline Week 0 & $61.3( \pm 5.9)$ & $62.1( \pm 12.2)$ & $536( \pm 266)$ & & & & 659 & 284 \\
\hline Week 32 & $37.8( \pm 10.7)$ & & $442( \pm 87)$ & $7.98( \pm 0.48)$ & $16.5( \pm 1.9)$ & $25.8( \pm 4.7)$ & 530 & 105 \\
\hline
\end{tabular}

Table 10. Synthesis method - Brand 2 (Group 2); Synthesis ingredients - Clandestine; Storage - Ambient.

\begin{tabular}{|c|c|c|c|c|c|c|c|c|}
\hline \multirow[b]{2}{*}{$\begin{array}{l}\text { Age of } \\
\text { sample }\end{array}$} & \multicolumn{6}{|c|}{ Headspace compound (ng) } & \multirow[b]{2}{*}{ Sum } & \multirow[b]{2}{*}{ Stdev } \\
\hline & Formaldehyde & Acetic acid & Formic acid & Formamide & $\begin{array}{l}\text { Dimethyl } \\
\text { formamide }\end{array}$ & $\begin{array}{c}\text { Trimethyl } \\
\text { amine }\end{array}$ & & \\
\hline Week 0 & $455( \pm 115)$ & $36.1( \pm 5.7)$ & $111( \pm 25)$ & & & & 602 & 146 \\
\hline Week 32 & $224( \pm 37)$ & & $6750( \pm 730)$ & $26.1( \pm 6.9)$ & $301( \pm 57)$ & $1220( \pm 190)$ & 8521 & 1021 \\
\hline
\end{tabular}

Table 11. Synthesis method - Brand 2 (Group 2); Synthesis ingredients - Clandestine; Storage - Freezer.

\begin{tabular}{|c|c|c|c|c|c|c|c|c|}
\hline \multirow[b]{2}{*}{$\begin{array}{l}\text { Age of } \\
\text { sample }\end{array}$} & \multicolumn{6}{|c|}{ Headspace compound (ng) } & \multirow[b]{2}{*}{ Sum } & \multirow[b]{2}{*}{ Stdev } \\
\hline & Formaldehyde & Acetic acid & Formic acid & Formamide & $\begin{array}{l}\text { Dimethyl } \\
\text { formamide }\end{array}$ & $\begin{array}{l}\text { Trimethyl } \\
\text { amine }\end{array}$ & & \\
\hline Week 0 & $63.1( \pm 8.1)$ & $37.6( \pm 3.8)$ & $128( \pm 19)$ & & & & 229 & 31 \\
\hline Week 32 & $175( \pm 96)$ & & $383( \pm 122)$ & $10.7( \pm 2.3)$ & $14.2( \pm 1.5)$ & $76.6( \pm 27.1)$ & 660 & 249 \\
\hline
\end{tabular}

